\title{
Does community violence exposure moderate the associations between maternal spanking and early child behavior problems?
}

\author{
Julie $\mathrm{Ma}^{1}$ (이 | Andrew Grogan-Kaylor ${ }^{2}$ | Shawna J. Lee ${ }^{2}$
}

${ }^{1}$ Department of Social Work, University of Michigan-Flint, Flint, Michigan

${ }^{2}$ School of Social Work, University of Michigan, Ann Arbor, Michigan

\section{Correspondence}

Julie Ma, Department of Social Work,

University of Michigan-Flint,

303 East Kearsley Street, Flint, MI.

Email: majul@umich.edu

\section{1 | INTRODUCTION}

Since the original investigation of Sears, Maccoby, and Levin (1957), there has been a long-standing research interest in the effect of parental discipline on child behavior. Over the last several decades a copious literature has emerged linking the use of parental physical punishment such as spanking to increases in children's behavior problems. This literature was summarized by Gershoff and Grogan-Kaylor (2016a) in their meta-analysis that reviewed 50 years of research on physical punishment. Across the corpus of literature included in their meta-analysis, these authors found that spanking is likely to promote rather than prevent child externalizing and internalizing behavior problems.

\begin{abstract}
A robust research literature links parental spanking with negative behavioral outcomes for children, however, it remains unclear whether conditions in the community may moderate the associations between spanking and behavior problems in early childhood. In the current study, we examined whether community violence exposure moderated the associations of maternal spanking with externalizing and internalizing behavior problems of young children. The sample used in this study was urban families and their children ages 3-5 $(n=2,472)$. We used fixed effects regression models, which yield stronger statistical control for baseline behavior problems, selection bias, and omitted variables bias. Mother's spanking was associated with elevated levels of both externalizing $(\beta=.037, p<.001)$ and internalizing $(\beta=.016, p<.001)$ behavior problems. Community violence exposure also predicted higher levels of externalizing $(\beta=.071, p<.01)$ and internalizing $(\beta=.043, p<.05)$ behavior problems. Community violence exposure did not moderate the associations between maternal spanking and behavior problems. Professionals working with families should promote the use of nonphysical disciplinary practices, regardless of the level of violence and crime in the community in which the family resides.
\end{abstract}

\section{KEYWORDS}

behavior problems, community violence exposure, fixed effects method, spanking 
suggested that the context in which parents discipline their children may moderate the associations of spanking and child behavior problems. The literature that has assessed this moderation hypothesis has not reached consensus. A stream of research highlights contextual factors as moderators of the link between physical punishment and child well-being, such that physically aggressive parenting is potentially less harmful in disadvantaged communities (e.g., Eamon, 2002). In contrast, this conditioning effect by social context was not found in other studies, suggesting that the associations between physical punishment and negative child outcomes are consistent regardless of neighborhood conditions (e.g., Grogan-Kaylor, 2005; Simons et al., 2002).

Theoretically, the notion that negative contextual conditions may moderate the associations between spanking and child behavior problems could potentially result in three contrasting hypotheses. The first is that community violence reduces the associations of spanking with child behavior problems. Some researchers suggest that in contexts in which residents are frequently victimized, or witness violent acts towards others, spanking may serve an adaptive function that prepares children for environmental challenges and physical danger in their community (Furstenberg, 1993; Ispa \& Halgunseth, 2004; McLoyd, 1990). The cost of child misbehavior may be higher in a disadvantaged neighborhood in which violence and crime are prevalent than it would be in more advantaged neighborhoods. Thus, parents may use more aggressive forms of punishment to prevent children from engaging in misbehavior that is more likely to result in damaging consequences in harsh neighborhood conditions (Button, 2008; Eamon, 2002). Cultural normativeness theory offers another explanation for this hypothesis (Deater-Deckard \& Dodge, 1997). As physically aggressive parenting practices are more common in socially disorganized contexts (Kohen, Leventhal, Dahinten, \& McIntosh, 2008; Krishnakumar, Narine, Roopnarine, \& Logie, 2014), the use of such disciplinary practices may be more widely accepted and justified in disadvantaged communities and may therefore have a weaker effect on child outcomes.

Another line of reasoning suggests that community violence might increase the associations of spanking with child behavior problems mainly because disadvantaged conditions may exacerbate stress and disrupt parental functioning thus contributing to poorer child well-being (Conger et al., 2002). Consistent with the tenets of the family stress model, when families and children are exposed to environmental stress from their neighborhoods, the association between spanking and negative child behavior could be exacerbated by the social context.

Lastly, there might be no moderating relationship of community violence on the associations of spanking with child behavior problems. Several studies have found little direct empirical support for the neighborhood moderation hypothesis and suggested that the associations between spanking and child outcomes are universal across contextual conditions (e.g., Grogan-Kaylor, 2005; Simons et al., 2002). These findings are in line with a growing body of literature that has consistently linked spanking with negative child outcomes regardless of social contexts such as country (Pace, Lee, \& Grogan-Kaylor, 2019), cultural normativeness (Gershoff et al., 2010), and race and ethnicity (Gershoff \& Grogan-Kaylor, 2016b; Gershoff, Lansford, Sexton, Davis-Kean, \& Sameroff, 2012; Ma \& Klein, 2018). It thus remains unclear whether the associations of parental spanking with child behavior problems may differ in disadvantaged social contexts with high levels of victimization and violence exposure.

\section{3 | BIDIRECTIONAL NATURE OF PARENTING AND CHILD BEHAVIOR}

Although the literature continues to highlight the primary role of parenting behavior in shaping child outcomes (Bornstein, 2006), some researchers argue that most studies concerning the association of spanking with child behavior have not adequately controlled for child effects (Larzelere, Gunnoe, \& Ferguson, 2018). Dysregulated behaviors and emotions of children are common putative causes for parental use of spanking in which the parent models the use of aggressive behavior and promotes subsequent child misbehavior (Lee, Altschul, \& Gershoff, 2013). To consider the potential bidirectional nature of parent-child interactions, extant spanking literature has employed cross-lagged designs (e.g., Lee, Altschul, \& Gershoff, 2013; Maguire-Jack, Gromoske, \& Berger, 2012) or controlled for children's existing behavior problems that may trigger the use of parental spanking (e.g., Grogan-Kaylor, 2005; Ma, Grogan-Kaylor, \& Lee, 2018).

\section{4 | CONFOUNDING VARIABLES AND SELECTION BIAS}

Interwoven with questions regarding the potential influence of contextual factors on parenting practices are concerns about the degree to which the observed effects of parental spanking and of a disadvantaged social context on child behavior are truly causal in nature, or are instead associations that could be attributed to the presence of other unobserved, heritable family characteristics that may have confounding relations with parenting behavior and child outcomes (Larzelere et al., 2018). Behavioral genetic studies have demonstrated the correlation of aggressive tendencies in the child and the parent (Arseneault et al., 2003). Thus, elements of familial genetic heritage shared by the child and the parent, such as dysregulated emotions and aggressive traits may be causes of child misbehavior that elicit disciplinary actions (Jaffee et al., 2004). Likewise, genetic mechanisms such as lack of impulse control may inform the way in which a parent responds to their child's misbehavior with the use of physically aggressive parenting practices (Lee, Brooks-Gunn, McLanahan, Notterman, \& Garfinkel, 2013). Yet, most physical punishment research fails to rule out this possibility of heritable characteristics possibly confounding the association of parental spanking with child misbehavior. 
Another potential bias in prior research that may account for the observed associations between disadvantaged social context and child behavior is the nonrandom selection of individuals and families into neighborhoods, based upon their socioeconomic status and racial and cultural background (Sampson, Morenoff, \& Gannon-Rowley, 2002). In the United States, economic inequality, racial discrimination, and spatial segregation remain strongly correlated with families' racial and cultural backgrounds (Massey, Gross, \& Shibuya, 1994). The prevalence of certain social behaviors such as crime and victimization in the community and family violence are likely to be correlated with parenting practices and child behavior. These possibly confounding factors, however, are not measured in most existing studies.

\section{5 | FIXED EFFECTS METHODS}

Long-standing work in econometrics has suggested a line of statistical investigation that may address some of the concerns in extant literature on parental spanking. Fixed effects regression methods are commonly used when longitudinal data and repeated measures are available (Allison, 2009; Wooldridge, 2010). Briefly, when there are longitudinal data that contain repeated measures of both the independent and dependent variables, the algebra of fixed effects regression allows every participant in the data set to effectively serve as their own statistical control (Stock \& Watson, 2003). Put more statistically, a fixed effects model controls for all time invariant characteristics of study subjects. Thus, characteristics of study subjects which remain constant over time, such as children's initial levels of behavior problems, or a parent's mean level of spanking over the course of the study period, are controlled for by the fixed effects regression model.

\section{6 | THE CURRENT STUDY}

To address the potential biases concerning omitted confounding factors and nonrandom selection into neighborhoods, and bidirectional effects in research concerning the role of social context and parenting on child development, we employ fixed effects regression to examine the moderating role of community violence exposure in the associations of physical punishment, or spanking, with children's behavior problems. By using only variation within the same family in the model, the estimates from fixed effects regression analyses are able to examine whether spanking predicts changes in behavior problems within the same child over time while accounting for the initial level of behavior problem scores as well as other nonmeasured, time-invariant variables. Our estimates are also consistent with recent suggestions that statistical examination of within child variation may be the most appropriate quantitative strategy to study the effects of parenting on child development (Berry \& Willoughby, 2017).

In view of prior research that has found that both community violence exposure and spanking are predictors of child behavior problems (Ma et al., 2018), we examine whether contextual conditions moderate the associations of maternal spanking with child behavior problems. Specifically, we hypothesize that community violence exposure would not moderate the associations between maternal spanking and early behavior problems. Our hypothesis is based in several lines of thinking. First, research has generally supported the notion that the strongest factors that predict child wellbeing are parenting behaviors, in other words, those factors that are most proximal to the child (McLoyd, 1990). Second, prior studies have examined potential moderators of the associations between parental spanking and child behavior problems, such as neighborhood context (Grogan-Kaylor, 2005), parent-child relationship quality (Berlin et al., 2009; Lee, Altschul, et al., 2013; Ma, Han, Grogan-Kaylor, Delva, \& Castillo, 2012; Ward, Lee, Pace, Grogan-Kaylor, \& Ma, 2019), race and ethnicity (Gershoff \& Grogan-Kaylor, 2016b; Ma \& Klein, 2018), cultural normativeness (Gershoff et al., 2010; Lansford et al., 2005) and country (Pace et al., 2019). Such studies generally did not find statistical evidence to demonstrate that family-level or communitylevel factors moderate the main effect linking parental use of spanking to child well-being.

\section{7 | METHOD}

\section{1 | Data}

Our analysis is based on data from the Fragile Families and Child Wellbeing Study (FFCWS). The FFCWS follows a cohort of 4,897 children who were born between 1998 and 2000 in 20 large US cities that had populations over 200,000 (see Reichman, Teitler, Garfinkel, \& McLanahan, 2001 for a detailed description of the data). Baseline in-person core surveys were conducted at hospitals after the child's birth with the mothers and the biological fathers (1,187 married and 3,710 unmarried). Follow-up core surveys were conducted over the phone when the child was age 1 (Wave 2), age 3 (Wave 3), age 5 (Wave 4), and age 9 (Wave 5). Mothers who participated in the Wave 3 and Wave 4 core surveys were also asked to take part in the supplemental In-Home assessments at their homes.

\section{2 | Sample}

Our analysis sample consisted of 2,472 families who participated in Wave 3 (child age 3 ) and Wave 4 (child age 5) In-Home assessments during which mothers reported child behavior problems, the outcomes of this study, and spanking and community violence, the main predictors. We employed a Multiple Imputation Through Chained Equations procedure in Stata 15 for the sample to account for missing data (StataCorp, 2017). Our imputation model included all variables in the analytic model. The estimates we report are based on 20 imputed data sets (Graham, Olchowski, \& Gilreath, 2007). 


\section{3 | Measures}

\subsection{1 | Child behavior problems}

During the Wave 3 and Wave 4 In-Home assessments, mothers reported their child's externalizing and internalizing problems at age 3 and age $5(0=$ not true, $1=$ somewhat or sometimes true, or 2 = very true or often true) using items from the $\mathrm{CBCL} / 2-3$ and the CBCL/4-18, respectively (Achenbach, 1991, 1992).

At Wave 3, when children were age 3, the average of mother's responses to 15 statements in the Aggressive Behavior subscale such as "Child is defiant," "Child hits others," and "Child gets in fights" approximated externalizing behavior $(\alpha=.86)$. At Wave 4 , when children were age 5, the mean of 20 items from the Aggressive Behavior subscale such as "Child is cruel, bullies and shows meanness to others," "Child destroys his/her own things," and "Child physically attacks people" represented externalizing behavior $(\alpha=.86)$.

Internalizing behavior at Wave 3 was drawn upon 24 items from the CBCL/2-3 Withdrawn-Depressed subscale (10 items; e.g., "Child doesn't know how to have fun, or he/she acts like little adult," "Child seems unresponsive to affection") and the Anxious-Depressed subscale (14 items; e.g., "Child looks unhappy without good reason," "Child is nervous, high strung, or tense") ( $\alpha=.81)$. At Wave 4 , 22 items from the CBCL/4-18 Withdrawn-Depressed subscale (9 items; e.g., "Child would rather be alone than with others" and "Child is underactive, slow moving, lacks energy") and the AnxiousDepressed subscale (14 items; e.g., "Child feels or complains no one loves him/her," "Child is unhappy, sad, or depressed") measured internalizing behavior $(\alpha=.76)$. One item, "Child is unhappy, sad, or depressed" was included in both subscales.

\subsection{2 | Mother's spanking in the past year}

During the Wave 3 and Wave 4 In-Home assessments, the Conflict Tactics Scale (Straus, Hamby, Finkelhor, Moore, \& Runyan, 1998) was used to measure mother's use of spanking in the preceding year $(0=$ this has never happened, 1 = once, $2=$ twice, $3=3-5$ times, $4=6-10$ times, $5=11-20$ times, $6=$ more than 20 times, $7=$ yes but not in the past year). To adequately represent mother's spanking in the past year, the last response category of this variable was recoded to 0 . Thus, the final response categories were $0=$ never, $1=$ once or twice, $2=3-10$ times, $3=11-20$ times, $4=$ more than 20 times.

\subsection{3 | Community violence exposure}

Exposure to community violence in the past year was represented by the mean score of the following seven items that were adapted from the My Exposure to Violence (Buka, Selner-O'Hagan, Kindlon, \& Earls, 1997), which has been validated by a large literature as an adequate measure of community violence exposure. During the
Wave 3 and Wave 4 In-Home assessments, mothers reported how many times in the past year they saw someone else get hit, slapped, punched, or beaten up by someone; were hit, slapped, punched, or beaten up by someone; saw someone else get attacked by someone with a weapon, like a knife or bat; were attacked by someone with a weapon; saw someone else get shot at by someone; were shot at by someone; and saw someone get killed because of violence by someone $(0=$ never, $1=$ once, $2=2-3$ times, $3=4-10$ times, $4=$ more than 10 times). Cronbach's $\alpha$ for this 7 -item scale was 0.72 at Wave 3 and 0.74 at Wave 4.

\subsection{4 | Covariates}

In our models, we controlled for a range of covariates at the parent, child, and neighborhood levels that prior literature has found to have associations with child behavior problems as well as parental use of spanking (e.g, Grogan-Kaylor, 2005; Ma et al., 2018).

\section{Mother's warmth}

Interviewers rated whether mothers showed warmth using the parental warmth subscale in the Early-Childhood HOME Inventory (Caldwell \& Bradley, 1984) during the Wave 3 and Wave 4 In-Home assessments. The average of five items such as "Parent spontaneously praised child at least twice" and "Parent's voice conveys positive feelings toward child" $(0=$ no, $1=$ yes $)$ represented mother's warmth at Wave $3(\alpha=0.72)$. At Wave 4 , a total of nine items measured maternal warmth $(\alpha=0.80)$. This scale added four items such as "Parent encourages child to contribute" and "Parent mentions skill of child" $(0=n o, 1=y e s)$ to the five items in the Wave 3 scale.

\section{Mother's depression}

During the Wave 3 and Wave 4 core interviews, mother's depressive symptoms were measured using the Composite International Diagnostic Interview-Short Form (CIDI-SF), Section A (Kessler, Andrews, Mroczek, Ustun, \& Wittchen, 1998). Mothers who endorsed the following stem question, "In the past year, have you felt sad or depressed for 2 weeks or more in a row?" $(0=$ no, $1=$ yes) were asked seven additional items on depressive symptoms such as feel tired out/low on energy, felt down or worthless, thought about death. Mothers who scored 3 or higher on this 8-item scale were classified as suffering from major depression. Cronbach's $\alpha$ for this scale was 0.97 at Wave 3 and 0.98 at Wave 4.

\section{Demographic variables}

Mother's age in years and child's age in months were available in the core interviews. Mothers reported their relationship status with the focal child's biological father $(1=$ married, $2=$ cohabiting, $3=$ not married or cohabiting) and household income during the core interviews. Household income was assessed using the following question, "Thinking about your income and the income of everyone else who lives with you, what was your total household income before taxes in the past 12 months?" Neighborhood income was the median income 
of the Census Tract in year 1999 in which the family was residing at the time of the Wave 3 and Wave 4 core interviews.

\section{4 | Analytic strategy}

We employed fixed effects regression with interaction terms to examine whether the associations of maternal spanking with children's behavior problems varied across the level of community violence. In this analysis, data were reshaped to have a long format where every child had multiple rows of data. Each row of data represented a measurement occasion for a particular child at a particular wave of the study. Thus, the model estimated was as follows:

$y_{i t}=\beta_{0}+\beta_{1}$ age $+\beta_{2}$ spanking $+\beta_{3}$ community violence

$+\beta_{4}$ spanking $\times$ community violence $+\Sigma \beta_{n}$ covariates $+u_{0 i}+e_{i t}$

Here $y_{i t}$ represented the behavioral outcomes for a child in family $i$ at time $t$. $\beta_{0}$ represented a regression intercept. $\beta_{1}$ was a covariate associated with the child's age while $\beta_{2}$ was the regression coefficient associated with the effect of mother's spanking. $\beta_{3}$ represented the regression coefficient associated with exposure to community violence, while $\beta_{4}$ represented the associated regression coefficient for the interaction of those community violence effects with maternal use of spanking. $\Sigma \beta_{n}$ were the regression coefficients associated with the other covariates. $u_{0 i}$ was an individual level intercept term, and $e_{i t}$ was an error term indicating the error in the regression for individual $i$ at time $t$.

\section{8 | RESULTS}

\section{1 | Descriptive statistics}

Table 1 shows results from univariate and bivariate analyses. From child age 3 to age 5 , the average of externalizing behavior (0.65 to 0.54$)$ and internalizing behavior $(0.40$ to 0.25$)$ scores decreased significantly $(p<.001)$. On average, mothers reported more frequent spanking when children were age 3 than age 5 $(p<.001)$. The average levels of maternal warmth $(0.89$ to 0.77$)$

TABLE 1 Descriptive characteristics $(n=2,472)$

\begin{tabular}{|c|c|c|c|}
\hline & \multicolumn{2}{|l|}{$M(S D)$ or $\%$} & \multirow[b]{2}{*}{$p$ Value } \\
\hline & Age 3 & Age 5 & \\
\hline Externalizing behavior & $0.65(0.39)$ & $0.54(0.32)$ & $<.001$ \\
\hline Internalizing behavior & $0.40(0.24)$ & $0.25(0.20)$ & $<.001$ \\
\hline Mother's spanking, past year & $1.68(1.34)$ & $1.43(1.27)$ & $<.001$ \\
\hline Never & $27 \%$ & $33 \%$ & \\
\hline Once or twice & $15 \%$ & $17 \%$ & \\
\hline $3-10$ times & $34 \%$ & $33 \%$ & \\
\hline $11-20$ times & $10 \%$ & $7 \%$ & \\
\hline More than 20 times & $14 \%$ & $9 \%$ & \\
\hline Community violence exposure, past year & $0.18(0.35)$ & $0.17(0.37)$ & .180 \\
\hline Mother's warmth & $0.89(0.22)$ & $0.77(0.28)$ & $<.001$ \\
\hline Mother's depression (\%) & $0.22(0.41)$ & $0.17(0.38)$ & $<.001$ \\
\hline Yes & $22 \%$ & $17 \%$ & \\
\hline No & $78 \%$ & $83 \%$ & \\
\hline \multicolumn{4}{|l|}{ Child demographics } \\
\hline Age (mo) & $35.26(2.21)$ & $61.11(2.42)$ & $<.001$ \\
\hline \multicolumn{4}{|l|}{ Mother's demographics } \\
\hline Age (y) & $28.08(6.01)$ & $30.21(6.01)$ & $<.001$ \\
\hline Relationship status & $2.20(0.87)$ & $2.26(0.90)$ & $<.001$ \\
\hline Married & $30 \%$ & $30 \%$ & \\
\hline Cohabiting & $20 \%$ & $13 \%$ & \\
\hline Not married or cohabiting & $50 \%$ & $57 \%$ & \\
\hline Household income (\$) & $34,763(44,854)$ & $36,636(44,057)$ & $<.01$ \\
\hline \multicolumn{4}{|l|}{ Neighborhood demographics } \\
\hline Median household income (\$) & $36,280(17,867)$ & $37,802(18,937)$ & $<.001$ \\
\hline
\end{tabular}

Note: $p$ values from paired sample $t$ tests. 
and mother's depression (0.22 to 0.17) was lower when children were age 5 than age $3(p<.001)$.

\section{2 | Fixed effects regressions}

Table 2 presents two fixed effects regression models that examined the associations of maternal spanking and community violence exposure with externalizing and internalizing behavior problems. These models also included an interaction term that tested the question whether the association of mother's spanking with children's behavior is dependent on contextual conditions.

Results showed that mother's spanking was associated with elevated levels of externalizing $(\beta=.037, p<.001)$ and internalizing $(\beta=.016, p<.001)$ behavior problems. Community violence exposure also predicted higher levels of externalizing $(\beta=0.071, p<.01)$ and internalizing $(\beta=.043, p<.05)$ behavior problems. These main predictors were linked to behavior problems even when the time-variant

TABLE 2 Fixed effects regression models on child behavior problems $(n=2,472)$

\begin{tabular}{|c|c|c|}
\hline & $\begin{array}{l}\text { Ext. } \\
\text { behavior }\end{array}$ & $\begin{array}{l}\text { Int. } \\
\text { behavior }\end{array}$ \\
\hline Mother's spanking, past year & $\begin{array}{l}0.037^{* * *} \\
(0.006)\end{array}$ & $\begin{array}{c}0.016^{* * *} \\
(0.004)\end{array}$ \\
\hline Community violence exposure, past year & $\begin{array}{c}0.071^{* *} \\
(0.026)\end{array}$ & $\begin{array}{c}0.043^{*} \\
(0.017)\end{array}$ \\
\hline Mother's spanking $\times$ community violence & $\begin{array}{c}-0.005 \\
(0.011)\end{array}$ & $\begin{array}{c}-0.004 \\
(0.007)\end{array}$ \\
\hline Mother's warmth & $\begin{array}{c}-0.032 \\
(0.022)\end{array}$ & $\begin{array}{c}-0.005 \\
(0.015)\end{array}$ \\
\hline Mother's depression & $\begin{array}{c}0.010 \\
(0.015)\end{array}$ & $\begin{array}{c}0.002 \\
(0.010)\end{array}$ \\
\hline Child age & $\begin{array}{c}-0.002 \\
(0.002)\end{array}$ & $\begin{array}{c}-0.003^{* *} \\
(0.001)\end{array}$ \\
\hline Mother's age & $\begin{array}{c}-0.018 \\
(0.019)\end{array}$ & $\begin{array}{c}-0.028^{*} \\
(0.013)\end{array}$ \\
\hline \multicolumn{3}{|l|}{ Relationship status: Married } \\
\hline Cohabiting & $\begin{array}{c}0.028 \\
(0.027)\end{array}$ & $\begin{array}{c}0.017 \\
(0.018)\end{array}$ \\
\hline Not married or cohabiting & $\begin{array}{c}0.010 \\
(0.026)\end{array}$ & $\begin{array}{c}0.038^{*} \\
(0.018)\end{array}$ \\
\hline Household income & $\begin{array}{c}0.000 \\
(0.000)\end{array}$ & $\begin{array}{l}-0.000 \\
(0.000)\end{array}$ \\
\hline Neighborhood income & $\begin{array}{c}-0.000 \\
(0.000)\end{array}$ & $\begin{array}{c}0.000 \\
(0.000)\end{array}$ \\
\hline Constant & $\begin{array}{c}1.201^{*} \\
(0.472)\end{array}$ & $\begin{array}{l}1.211^{* * *} \\
(0.320)\end{array}$ \\
\hline
\end{tabular}

${ }^{*} p<0.05$.

${ }^{* *} p<0.01$.

${ }^{* * *} p<.001 ;$ standard errors in parentheses. covariates in the models as well as characteristics of study participants that did not change over time were controlled for. The associations of maternal spanking with both externalizing and internalizing behavior problems were not moderated by community violence exposure. Maternal warmth and depression did not have an association with externalizing or internalizing behavior problems after accounting for all time-invariant characteristics of the child and the family.

\section{DISCUSSION}

In the current study, we examined whether the associations of maternal spanking with child behavior problems were moderated by social context. In other words, we tested the notion that spanking may be beneficial or have no harm to children who live in communities marked with higher levels of victimization and violence, as compared to children who live in community contexts with lower levels of victimization and violence (Eamon, 2002). Consistent with our hypothesis, study results indicated that community violence exposure did not moderate the main effects of maternal spanking on externalizing and internalizing behavior problems of children.

Our findings were consistent with numerous prior studies of the FFCWS, in that we found the associations of maternal spanking with elevated levels of both externalizing and internalizing child behavior problems (Ma \& Grogan-Kaylor, 2017; Maguire-Jack et al., 2012; Taylor, Manganello, Lee, \& Rice, 2010). Also consistent with a prior FFCWS study that used fixed effects analysis, we found that community violence predicted higher levels of child aggression (Ma et al., 2018). In this study, fixed effects regression models showed that mother's spanking is linked to increased levels of child behavior problems regardless of the level of community violence. These associations held even after controlling for initial level of behavior problems of children, selection bias, omitted variables, and all potential time-invariant confounding variables that may have associations with the predictors and outcomes that were present at the beginning of the study period.

The basic finding that spanking is associated with negative outcomes for children is, at this point, well supported by numerous studies (Gershoff et al., 2018; Holden, Grogan-Kaylor, Durrant, \& Gershoff, 2017). Even so, this study makes an important contribution to our understanding of the social contexts in which spanking may or may not increase negative child behaviors. Specifically, prior research that examined moderators of the associations between parental physical punishment and child behavior problems (e.g., Berlin et al., 2009; Gershoff \& Grogan-Kaylor, 2016b; Gershoff et al., 2012; Lee, Altschul, \& Gershoff, 2013; Ma \& Klein, 2018; Stacks, Oshio, Gerard, \& Roe, 2009; Ward et al., 2019) have generally failed to demonstrate that there are factors that moderate the main association linking parental use of spanking to child wellbeing. Even in studies that find some degree of moderation of the effect of physical punishment (Gershoff et al., 2010; Lansford et al., 2005; 
Pace et al., 2019), there is no moderation to such a degree that spanking is seen to be beneficial in any particular country or social context. Put differently, there is little to no empirical evidence in support of physical punishment, including the belief articulated by some parents that spanking is the most effective strategy to "protect" their children from violent environmental conditions. In fact, research would suggest that the best form of protection from community violence is a loving and caring parent-child relationship (Buka, Stichick, Birdthistle, \& Earls, 2001; Plybon \& Kliewer, 2001) in which parents discipline their child without physical force.

The substantive effect for maternal spanking on the study outcomes was 0.09 of a standard deviation for externalizing behavior and 0.05 of a standard deviation for internalizing behavior. The magnitude of these effect sizes is modest, but comparable to that reported in extant literature (Gershoff \& Grogan-Kaylor, 2016a). A recent meta-analytic review of the literature on the effects of spanking has contended that most prior findings have failed to control for behavioral issues at baseline and alternative factors that predict spanking and child outcomes (Larzelere et al., 2018). The effect sizes reported herein from fixed effects regression eliminate these possible methodological flaws by controlling for pre-existing behavior problems of children and all time-invariant confounds. Furthermore, these effects sizes are likely to be an underestimate of the true associations between spanking and child behavior problems as fixed effects method focuses on the within-person change only and does not utilize any between-subject variation in the estimates. The use of within-person variation in our statistical procedures also addresses a related methodological argument in the literature that suggests that only variation within a child can accurately demonstrate the effects of spanking on developmental processes (Berry \& Willoughby, 2017).

\section{1 | Implications for practice and policy}

The results of this study support the basic supposition put forth by McLoyd (1990) that the parent-child relationship is the most critical element for promoting child well-being. Ultimately, efforts to promote child wellbeing-including among those children living in community contexts marked by high levels of community violence-must focus on helping parents to understand how they can buffer children from violence and aggression both in the community and in the home without the use of spanking as a form of misguided discipline.

The current study findings underscore the need to advise parents to use non-violent disciplinary practices regardless of their environmental conditions. Parent education programs that encourage the use of nonphysical discipline should be made available and accessible in every community, as children living in communities with more prevalent crime and violence as well as in more advantaged communities are shown to be equally vulnerable to the effects of spanking on behavior problems. Triple $\mathrm{P}$ is unique among parenting programs in that it integrates a community-level, public health approach with family-level services to promote alternatives to physical punishment of children. Given its multi-level approach to promoting positive parenting behaviors and child wellbeing, that includes the use of community-level campaigns to support positive parenting, Triple $\mathrm{P}$ may be one of the most relevant evidence-based intervention programs that addresses community- and family-level factors to reduce children's exposure to spanking (Prinz, 2020).

Finally, the current study provides empirical evidence to further support the recent Resolution on Physical Discipline of Children By Parents issued by the American Psychological Association (2019), which encourages professionals to educate the public about the potential harms of physical punishment and advise parents against the use of spanking. Furthermore, our findings provide empirical support to advance policy reforms in the United States to join the global movement of an increasing number of countries that have legally protected children against any form of family violence, including parental use of physical punishment (Global Initiative to End All Corporal Punishment of Children, 2019).

\section{2 | Limitations and considerations for future research}

As with all research, the present analysis was limited in several ways. Most of the measures employed in this study were based upon parent self-report. Self-report measures, particularly those about undesirable behaviors, may be subject to social desirability concerns in reporting. It is possible, therefore, that mothers may have underreported the degree to which they spanked their child. Likewise, mothers may have under-reported or mis-reported problematic conditions in their communities and their child's behavior problems. It is thus notable that despite the potential for under-reporting of use of spanking, there are nonetheless associations between this widely used parenting practice and increases in child behavior problems. An important direction for future research is to verify the current findings using multiple data sources that are more objective such as administrative data.

Observational data are always limited in some regard in the degree to which they can provide causal conclusions. Also, the fixed effects method does not provide parameter estimates for predictors that do not change over time (e.g., race and ethnicity). With that caveat in mind, the approach undertaken in this study has a number of strengths, most notably that the fixed effects regression models rule out possible unobserved confounding variables which might pose threats to causal inferences. Thus, the findings in this study might be understood to be stronger than conclusions in previous research about the interaction of parenting and community violence and the main effects of parenting and community violence on child behavior.

Finally, we note that an additional concern of the analyses reported herein is that the key independent variable-maternal spanking-most likely does not capture the full extent of children's exposure to physical punishment. For example, children are often spanked by other caregivers, such as fathers. However, it is worth noting that research studies show that even in two-parent families, 
mothers use spanking more often than fathers (Lee, Altschul, \& Gershoff, 2015), and in analyses that examined the longitudinal transactional relations between maternal and paternal spanking and child behavior problems, it was mother's spanking only-and not father's spanking-that was associated with child behavior problems (Lee et al., 2015). Nonetheless, it would be optimal to capture the full range of children's exposure to spanking, which could be an important direction for future research.

\section{0 | CONCLUSION}

The findings of this study underscore that maternal spanking is associated with increased levels of externalizing and internalizing behavior problems of young children, irrespective of the level of community violence exposure. The use of fixed effects regression strengthens the notion that spanking predicts adverse child behavior by statistically controlling for alternative explanations such as baseline child behavior problems, omitted variables, and selection. Consistent with the recommendations of professional organizations such as the American Academy of Pediatrics (Sege, Siegel, AAP Council on Child Abuse \& Neglect, \& AAP Committee on Psychosocial Aspects of Child \& Family Health, 2018) and the American Psychological Association (American Psychological Association, 2019), our findings support the burgeoning evidence against the spanking of children.

\section{ORCID}

\section{Julie Ma ID http://orcid.org/0000-0003-4644-6262}

\section{REFERENCES}

Achenbach, T. M. (1991). Integrative guide for the $1991 \mathrm{CBCL} / 4-18$, YSR, and TRF profiles. Burlington: University of Vermont.

Achenbach, T. M. (1992). Manual for the child behavior checklist/2-3 and 1992 profile. Burlington: University of Vermont.

Allison, P. D. (2009). Fixed effects regression models (160). New York: Sage publications.

American Psychological Association. (2019). Resolution on physical discipline of children by parents. https://www.apa.org/about/policy/ physical-discipline.pdf

Arseneault, L., Moffitt, T. E., Caspi, A., Taylor, A., Rijsdijk, F. V., Jaffee, S. R., ... Measelle, J. R. (2003). Strong genetic effects on crosssituational antisocial behaviour among 5 -year-old children according to mothers, teachers, examiner-observers, and twins' self-reports. Journal of Child Psychology and Psychiatry, 44, 832-848. https://doi. org/10.1111/1469-7610.00168

Berlin, L. J., Ispa, J. M., Fine, M. A., Malone, P. S., Brooks-Gunn, J., Brady-Smith, C., ... Bai, Y. (2009). Correlates and consequences of spanking and verbal punishment for low-income White, African American, and Mexican American toddlers. Child Development, 80, 1403-1420. https://doi.org/10.1111/j.1467. 8624.2009.01341.x

Berry, D., \& Willoughby, M. T. (2017). On the practical interpretability of cross-lagged panel models: Rethinking a developmental workhorse. Child Development, 88, 1186-1206. https://doi.org/10.1111/cdev. 12660
Bornstein, M. H. (2006). Parenting: Science and practice. In I. E. Sigel \& K. A. Renninger (Eds.), Handbook of child psychology, child psychology and practice (pp. 892-949). New York: Wiley.

Buka, S. L., Selner-O'Hagan, M. B., Kindlon, D. J., \& Earls, F. J. (1997). The "My Exposure to Violence Interviews"; Administration and Scoring Manual. Boston, MA: Harvard School of Public Health. (Version 3).

Buka, S. L., Stichick, T. L., Birdthistle, I., \& Earls, F. J. (2001). Youth exposure to violence: Prevalence, risks, and consequences. American Journal of Orthopsychiatry, 71, 298-310. https://doi.org/10.1037/ $0002-9432.71 .3 .298$

Button, D. M. (2008). Social disadvantage and family violence: Neighborhood effects on attitudes about intimate partner violence and corporal punishment. American Journal of Criminal Justice, 33, 130-147. https://doi.org/10.1007/s12103008-9033-3

Caldwell, B. M., \& Bradley, R. H. (1984). Home observation for measurement of the environment. Little Rock: University of Arkansas.

Conger, R. D., Wallace, L. E., Sun, Y., Simons, R. L., McLoyd, V. C., \& Brody, G. H. (2002). Economic pressure in African American families: A replication and extension of the family stress model. Developmental Psychology, 38(2), 179-193.

Deater-Deckard, K., \& Dodge, K. A. (1997). Externalizing behavior problems and discipline revisited: Nonlinear effects and variation by culture, context, and gender. Psychological inquiry, 8, 161-175. https://doi.org/10.1207/s15327965pli0803_1

Eamon, M. K. (2002). Poverty, parenting, peer, and neighborhood influences on young adolescent antisocial behavior. Journal of Social Service Research, 28, 1-23. https://doi.org/10.1300/ J079v28n01_01

Furstenberg, F. F. (1993). How families manage risk and opportunity in dangerous neighborhoods. In W. J. Wilson (Ed.), Sociology and the public agenda (pp. 231-258). Newbury Park, CA: Sage. https://doi.org/ 10.4135/9781483325484.n12

Gershoff, E. T., Goodman, G. S., Miller-Perrin, C. L., Holden, G. W., Jackson, Y., \& Kazdin, A. E. (2018). The strength of the causal evidence against physical punishment of children and its implications for parents, psychologists, and policymakers. American Psychologist, 73, 626-638. https://doi.org/10.1037/amp0000327

Gershoff, E. T., \& Grogan-Kaylor, A. (2016a). Spanking and child outcomes: Old controversies and new meta-analyses. Journal of Family Psychology, 30, 453-469. https://doi.org/10.1037/fam0000191

Gershoff, E. T., \& Grogan-Kaylor, A. (2016b). Race as a moderator of associations between spanking and child outcomes. Family Relations, 65, 490-501. https://doi.org/10.1111/fare.12205

Gershoff, E. T., Grogan-Kaylor, A., Lansford, J. E., Chang, L., Zelli, A., Deater-Deckard, K., \& Dodge, K. A. (2010). Parent discipline practices in an international sample: Associations with child behaviors and moderation by perceived normativeness. Child Development, 81, 487-502. https://doi.org/10.1111/j.1467-8624. 2009.01409.x

Gershoff, E. T., Lansford, J. E., Sexton, H. R., Davis-Kean, P., \& Sameroff, A. J. (2012). Longitudinal links between spanking and children's externalizing behaviors in a national sample of White, Black, Hispanic, and Asian American families. Child Development, 83(3), 838-843. https://doi.org/10.1111/j.14678624.2011.01732.x

Global Initiative to End All Corporal Punishment of Children. (2019). Global report 2018: Progress towards ending corporal punishment of children. http://endcorporalpunishment.org/wp-content/uploads/ global/Global-report-2018-spreads.pdf

Graham, J. W., Olchowski, A. E., \& Gilreath, T. D. (2007). How many imputations are really needed? Some practical clarifications of multiple imputation theory. Prevention Science, 8, 206-213. https:// doi.org/10.1007/s11121-007-0070-9 
Grogan-Kaylor, A. (2005). Relationship of corporal punishment and antisocial behavior by neighborhood. Archives of Pediatrics \& Adolescent Medicine, 159, 938-942. https://doi.org/10.1001/ archpedi.159.10.938

Holden, G. W., Grogan-Kaylor, A., Durrant, J. E., \& Gershoff, E. T. (2017). Researchers deserve a better critique: Response to Larzelere, Gunnoe, Roberts, and Ferguson (2017). Marriage \& Family Review, 53, 465-490. https://doi.org/10.1080/01494929.2017.1308899

Ispa, J. M., \& Halgunseth, L. C. (2004). Talking about corporal punishment: Nine low-income African American mothers' perspectives. Early Childhood Research Quarterly, 19, 463-484. https://doi.org/10.1016/j. ecresq.2004.07.002

Jaffee, S. R., Caspi, A., Moffitt, T. E., Polo-Tomas, M., Price, T. S., \& Taylor, A. (2004). The limits of child effects: Evidence for genetically mediated child effects on corporal punishment but not on physical maltreatment. Developmental Psychology, 40, 1047-1058. https://doi.org/10.1037/0012-1649.40.6.1047

Kessler, R. C., Andrews, G., Mroczek, D., Ustun, B., \& Wittchen, H.-U. (1998). The World Health Organization Composite International Diagnostic Interview short-form (CIDI-SF). International Journal of Methods in Psychiatric Research, 7, 171-185. https://doi.org/10.1002/ mpr.47

Kohen, D. E., Leventhal, T., Dahinten, V. S., \& McIntosh, C. N. (2008). Neighborhood disadvantage: Pathways of effects for young children. Child Development, 79, 156-169. https://doi.org/10.1111/j.14678624.2007.01117.x

Krishnakumar, A., Narine, L., Roopnarine, J. L., \& Logie, C. (2014). Multilevel and cross-level effects of neighborhood and family influences on children's behavioral outcomes in Trinidad and Tobago: The intervening role of parental control. Journal of Abnormal Child Psychology, 42, 1057-1068. https://doi.org/10.1007/ s10802-014-9852-2

Lansford, J. E., Chang, L., Dodge, K. A., Malone, P. S., Oburu, P., Palmérus, K., ... Quinn, N. (2005). Physical discipline and children's adjustment: Cultural normativeness as a moderator. Child Development, 76, 1234-1246. https://doi.org/10.1111/j.1467-8624. 2005.00847.x

Larzelere, R. E., Gunnoe, M. L., \& Ferguson, C. J. (2018). Improving causal inferences in meta-analyses of longitudinal studies: Spanking as an illustration. Child Development, 89, 2038-2050. https://doi.org/10. 1111/cdev.13097

Lee, D., Brooks-Gunn, J., McLanahan, S. S., Notterman, D., \& Garfinkel, I. (2013). The great recession, genetic sensitivity, and maternal harsh parenting. Proceedings of the National Academy of Sciences, 110, 13780-13784. https://doi.org/10.1073/pnas.1312398110

Lee, S. J., Altschul, I., \& Gershoff, E. T. (2013). Does warmth moderate longitudinal associations between maternal spanking and child aggression in early childhood? Developmental Psychology, 49, 2017-2028. https://doi.org/10.1037/a0031630

Lee, S. J., Altschul, I., \& Gershoff, E. T. (2015). Wait until your father gets home? Mother's and fathers' spanking and development of child aggression. Children and Youth Services Review, 52, 158-166. https://doi.org/10.1016/j.childyouth.2014.11.006

Leventhal, T., \& Brooks-Gunn, J. (2000). The neighborhoods they live in: The effects of neighborhood residence on child and adolescent outcomes. Psychological Bulletin, 126, 309-337. https://doi.org/10. 1037/0033-2909.126.2.309

Ma, J., \& Grogan-Kaylor, A. (2017). Longitudinal associations of neighborhood collective efficacy and maternal corporal punishment with behavior problems in early childhood. Developmental Psychology, 53(6), 1027-1041. https://doi.org/10.1037/dev0000308

Ma, J., Grogan-Kaylor, A., \& Lee, S. J. (2018). Associations of neighborhood disorganization and maternal spanking with children's aggression: A fixed-effects regression analysis. Child Abuse \& Neglect, 76, 106-116. https://doi.org/10.1016/j.chiabu.2017.10.013
Ma, J., Han, Y., Grogan-Kaylor, A., Delva, J., \& Castillo, M. (2012). Corporal punishment and youth externalizing behavior in Santiago, Chile. Child Abuse \& Neglect, 36(6), 481-490. https://doi.org/10.1016/j. chiabu.2012.03.006

Ma, J., \& Klein, S. (2018). Does race/ethnicity moderate the associations between neighborhood and parenting processes on early behavior problems? Journal of Child and Family Studies, 27, 3717-3729. https:// doi.org/10.1007/s10826-018-1200-7

Maguire-Jack, K., Gromoske, A. N., \& Berger, L. M. (2012). Spanking and child development during the first 5 years of life. Child Development, 83, 1960-1977. https://doi.org/10.1111/j.1467-8624.2012.01820.x

Massey, D. S., Gross, A. B., \& Shibuya, K. (1994). Migration, segregation, and the geographic concentration of poverty. American Sociological Review, 59, 425-445. https://doi.org/10.2307/2095942

McLoyd, V. C. (1990). The impact of economic hardship on Black families and children: Psychological distress, parenting, and socioemotional development. Child Development, 61, 311-346. https://doi.org/10. 2307/1131096

Pace, G. T., Lee, S. J., \& Grogan-Kaylor, A. (2019). Spanking and young children's socioemotional development in low- and middle-income countries. Child Abuse \& Neglect, 88, 84-95. https://doi.org/10.1016/j. chiabu.2018.11.003

Plybon, L. E., \& Kliewer, W. (2001). Neighborhood types and externalizing behavior in urban school-age children: Tests of direct, mediated, and moderated effects. Journal of Child and Family Studies, 10, 419-437. https://doi.org/10.1023/ A: 1016781611114

Prinz, R. J. (2020). Triple P-Positive parenting program. In E. T. Gershoff \& S. J. Lee (Eds.), Ending the physical punishment of children: A guide for clinicians and practitioners (pp. 133-143). Washington, DC: American Psychology Association.

Reichman, N. E., Teitler, J. O., Garfinkel, I., \& McLanahan, S. S. (2001). Fragile families: Sample and design. Children and Youth Services Review, 23, 303-326. https://doi.org/10.1016/S0190-7409(01) 00141-4

Sampson, R. J., Morenoff, J. D., \& Gannon-Rowley, T. (2002). Assessing "neighborhood effects": Social processes and new directions in research. Annual Review of Sociology, 28, 443-478. https://doi.org/ 10.1146/annurev.soc.28.110601.141114

Sears, R. R., Maccoby, E. E., \& Levin, H. (1957). Patterns of child rearing. New York: Harper \& Row.

Sege, R. D., \& Siegel, B. S., AAP Council on Child Abuse and Neglect, AAP Committee on Psychosocial Aspects of Child and Family Health. (2018). Effective discipline to raise healthy children. Pediatrics, 142, e20183112. https://doi.org/10.1542/peds.2018-3112

Simons, R. L., Lin, K.-H., Gordon, L. C., Brody, G. H., Murry, V., \& Conger, R. D. (2002). Community differences in the association between parenting practices and child conduct problems. Journal of Marriage and Family, 64, 331-345. https://doi.org/10.1111/j.17413737.2002.00331.x

Stacks, A. M., Oshio, T., Gerard, J., \& Roe, J. (2009). The moderating effect of parental warmth on the association between spanking and child aggression: A longitudinal approach. Infant and Child Development, 18, 178-194.

StataCorp. (2017). Stata statistical software: Release 15. College Station, TX: StataCorp LLC.

Stock, J. H., \& Watson, M. W. (2003). Introduction to econometrics (04). Boston: Addison-Wesley. [Retrieved from. http://www.ssc.wisc.edu/ $\sim$ munia/475/InstVaReg.pdf]

Straus, M. A., Hamby, S. L., Finkelhor, D., Moore, D. W., \& Runyan, D. (1998). Identification of child maltreatment with the ParentChild Conflict Tactics Scales: Development and psychometric data for a national sample of American parents. Child Abuse \& Neglect, 22(4), 249-270. https://doi.org/10.1016/S0145-2134(97) 00174-9 
Taylor, C. A., Manganello, J. A., Lee, S. J., \& Rice, J. C. (2010). Mothers' spanking of 3-year-old children and subsequent risk of children's aggressive behavior. Pediatrics, 125, e1057-e1065. https://doi.org/10. 1542/peds.2009-2678

Ward, K. P., Lee, S. J., Pace, G. T., Grogan-Kaylor, A., \& Ma, J. (2019). Attachment style and the association of spanking and child externalizing behavior. Academic Pediatrics.

Wooldridge, J. M. (2010). Econometric analysis of cross section and panel data. Cambridge, MA; London, England: MIT Press.
How to cite this article: Ma J, Grogan-Kaylor A, Lee SJ. Does community violence exposure moderate the associations between maternal spanking and early child behavior problems? Aggressive Behavior. 2020;46:210-219. https://doi.org/10.1002/ab.21882 